\title{
Residual and recurrent gradients after septal myectomy for hypertrophic cardiomyopathy-mechanisms of obstruction and outcomes of reoperation
}

\author{
Yang Hyun Cho, MD, PhD, a,b Eduard Quintana, MD, FETCS, ${ }^{\mathrm{a}, \mathrm{c}}$ Hartzell V. Schaff, MD, ${ }^{\mathrm{a}}$ \\ Rick A. Nishimura, MD, ${ }^{\mathrm{d}}$ Joseph A. Dearani, MD, ${ }^{\mathrm{a}}$ Martin D. Abel, MD, ${ }^{\mathrm{e}}$ and Steve Ommen, $\mathrm{MD}^{\mathrm{d}}$
}

\begin{abstract}
Objective: The aims of the present study were to identify the mechanisms of residual or recurrent left ventricular outflow tract obstruction in patients undergoing repeat septal myectomy for hypertrophic cardiomyopathy and to assess the early and late results of reoperation.
\end{abstract}

\begin{abstract}
Methods: From January 1980 to June 2012, we performed 52 repeat myectomies in 51 patients. We reviewed the medical records and preoperative transthoracic echocardiograms to evaluate the adequacy of the previous resection and mechanism of left ventricular outflow tract obstruction. The complications of previous and repeat myectomy, New York Heart Association class, and survival were analyzed.
\end{abstract}

\begin{abstract}
Results: The mean interval from previous myectomy to reoperation was $43 \pm 51$ months. In 6 patients (12\%) residual or recurrent gradients were caused by isolated midventricular obstruction. In the remaining 46 operations, the mechanism of residual or recurrent gradients was identified as systolic anterior motion of mitral valverelated subaortic obstruction caused by inadequate length of previous subaortic septal excision in 31 patients (59\% of the total), both an inadequate length and an inadequate depth of septectomy in 13 patients $(25 \%)$, and both residual subaortic obstruction due to systolic anterior motion of the mitral valve and midventricular obstruction in 2 patients (4\%). Preoperatively, 96\% of patients were in New York Heart Association class III or IV; postoperatively, $93.8 \%$ were in class I or II $(P<.001)$. The 10 -year survival after reoperation was $98 \%$ and similar to that of an age- and gender-matched Minnesota population $(P=.46)$.
\end{abstract}

Conclusions: The most common cause of recurrent left ventricular outflow tract obstruction and symptoms in patients undergoing septal myectomy has been an inadequate length of septal excision. Reoperation is safe, with excellent long-term survival and functional improvement. (J Thorac Cardiovasc Surg 2014;148:909-16)

Fixed or provocable left ventricular (LV) outflow tract (LVOT) obstruction will be present in as many as $70 \%$ of patients with hypertrophic cardiomyopathy (HCM). ${ }^{1}$ In obstructive HCM, LVOT narrowing will be caused by septal hypertrophy combined with systolic anterior motion of the mitral valve (SAM); an abnormal papillary muscle can also contribute to LVOT gradients. ${ }^{2}$ Patients unresponsive to medical treatment and with favorable anatomy are good candidates for septal myectomy, which can predictably

\footnotetext{
From the Division of Cardiovascular Surgery, ${ }^{\text {a }}$ Mayo Clinic, Rochester, Minn; Department of Thoracic and Cardiovascular Surgery, ${ }^{\mathrm{b}}$ Samsung Medical Center, Sungkyunkwan University School of Medicine, Seoul, Korea; University of Barcelona, ${ }^{\mathrm{c}}$ Barcelona, Spain; Division of Cardiovascular Disease ${ }^{\mathrm{d}}$ and Department of Anesthesiology, ${ }^{\mathrm{e}}$ Mayo Clinic, Rochester, Minn.

Disclosures: Authors have nothing to disclose with regard to commercial support.

Drs Y.H.C. and E.Q. contributed equally to this work.

Read at the 94th Annual Meeting of The American Association for Thoracic

Surgery, Toronto, Ontario, Canada, April 26-30, 2014.

Received for publication April 1, 2014; revisions received April 22, 2014; accepted for publication May 5, 2014; available ahead of print June 13, 2014.

Address for reprints: Hartzell V. Schaff, MD, Division of Cardiovascular Surgery,

Mayo Clinic College of Medicine, 200 First St SW, Rochester, MN 55905

(E-mail: schaff@mayo.edu).

$0022-5223 / \$ 36.00$

Copyright (c) 2014 by The American Association for Thoracic Surgery

http://dx.doi.org/10.1016/j.jtcvs.2014.05.028
}

relieve gradients and secondary mitral valve regurgitation, improving symptoms and exercise performance. ${ }^{3,4} \mathrm{~A}$ subset of patients undergoing myectomy can have residual or recurrent obstruction with symptom persistence, and although the risk of residual gradients is low, little is known about the mechanisms of recurrent obstruction or outcomes of reoperation. ${ }^{5}$ Therefore, the aim of the present study was to investigate the anatomic abnormalities leading to reoperation for myectomy and to document the early and late results of reoperation.

\section{METHODS \\ Patient Selection}

From January 1980 to June 2012, 2034 patients underwent septal myectomy for obstructive HCM at our clinic. Of these patients, we identified 51 who had undergone 52 operations for residual or recurrent obstruction after previous surgical septal myectomy. We included only patients who had a primary diagnosis of HCM and did not include patients who had undergone myectomy concurrent with planned aortic valve replacement or patients who had developed SAM after mitral valve repair. The Mayo Clinic College of Medicine institutional review board reviewed and approved the present clinical study, and all patients agreed to clinical research authorization before surgery. To capture the data related to this population, we used the information from our database and electronic medical records. Follow-up data were obtained from health assessment questionnaires sent to the patients and families 1, 3, 5, 10, and 15 years postoperatively and was 


\section{Abbreviations and Acronyms \\ HCM = hypertrophic cardiomyopathy \\ $\mathrm{LV}=$ left ventricular \\ LVOT $=$ LV outflow tract \\ $\mathrm{SAM}=$ systolic anterior motion of mitral valve}

supplemented by written correspondence from the referral physicians or the patients themselves; vital status was determined from the Social Security Death Index.

All patients had at rest or provoked gradients of $\geq 50 \mathrm{~mm} \mathrm{Hg}$ determined preoperatively using transthoracic Doppler echocardiography or an invasive hemodynamic study if the outflow tract gradients could not be determined by Doppler echocardiography. Echocardiographic studies were performed at baseline according to the recommendations of the American Society of Echocardiography. ${ }^{3}$ The LVOT gradients were measured using continuous-wave Doppler of the outflow tract from an apical window and calculated using the modified Bernoulli equation $\left(\right.$ gradient $=4 \mathrm{v}^{2}, \mathrm{v}=$ peak LVOT velocity). If a significant gradient was not obtained under basal conditions, a Valsalva maneuver and/or administration of amyl nitrate or exercise was used to provoke a gradient. If the patients were stable in the operating room before cardiopulmonary bypass, pressure measurements were obtained again by directly measuring the intracavitary (LV) and aortic pressures. $^{6}$

Of the 52 patients, 32 had undergone their first operation for septal myectomy elsewhere. The remaining 20 patients had undergone their initial operation at our institution, representing approximately $1 \%$ of patients undergoing primary myectomy. Two patients had residual obstruction after 2 previous myectomies, and 3 patients had undergone previous percutaneous alcohol septal ablation.

\section{Recurrent Obstruction Etiology}

The site of recurrent obstruction was identified primarily using a parasternal long-axis view. Images of the preoperative echocardiograms and operative records of all the patients were reviewed by 3 of us (Y.H.C., E.Q., and H.V.S.). In each patient, consensus was reached regarding the morphologic features causing obstruction. The previous myectomy site was visually evaluated. The presence of SAM was a marker of dynamic LVOT obstruction, indicating residual or recurrent subaortic obstruction. A midventricular obstructive pattern was defined when no SAM was present and the midventricular septum was responsible for a significant intracavitary gradient. The anatomy of the papillary muscle was also reviewed as a possible cause of LVOT obstruction. From these findings, we categorized the mechanisms of recurrent obstructions as an insufficient length of septal excision, an inadequate depth of septal excision, midventricular obstruction, or obstruction due to an abnormal papillary muscle (Figure 1).

An important goal of the present study was to determine whether late LVOT obstruction might reflect regrowth of the muscle in the area of previous myectomy. Thus, we analyzed further those patients from our clinic who had had marked improvement in their clinical status initially after the previous myectomy. We then compared the Doppler echocardiograms obtained early after initial myectomy with the studies obtained before reoperation to compare the septal anatomy and previous myectomy site.

\section{Surgical Procedure}

The operations were performed using standard methods for repeat median sternotomy, including normothermic cardiopulmonary bypass with single venous cannula and antegrade cold blood cardioplegia for myocardial protection. Exposure is facilitated by complete lysis of adhesions to allow the ventricles to collapse and be displaced posteriorly. Next, an oblique aortotomy is made; we have preferred to situate this slightly closer to the sinotubular ridge than usual for aortic valve replacement. The aortic incision is carried through the midpoint of the noncoronary aortic sinus of Valsalva to a level approximately $1 \mathrm{~cm}$ above the valve annulus. The edge of the proximal aorta is held out of the way with small stay sutures, and a cardiotomy sucker is placed through the aortic valve and used to depress the anterior leaflet of the mitral valve to protect it from injury. The right aortic valve cusp is collapsed against the sinus wall, where it will usually stay.

The region of residual septal obstruction can be recognized by the endocardial scar resulting from contact with the anterior mitral valve leaflet. The technique used for relief of residual subaortic obstruction is similar to that used for primary operations. ${ }^{7}$ The septum is incised with a no. 10 scalpel blade just to the right of the nadir of the right aortic sinus. Incision in the septum should be made upward and then leftward over to the anterior leaflet of the mitral valve. We use scissors to complete excision of this initial portion of the myocardium. A sponge stick is used to depress the right ventricle and to rotate the septum posteriorly, orienting the LV outflow anteriorly. The area of septal excision is then deepened and lengthened toward the apex of the heart, being certain to excise the hypertrophied septum beyond endocardial scar. Next, the myectomy site is further enlarged using pituitary rongeurs. An adequate septal myectomy will usually yield 3 to 12 $\mathrm{g}$ of muscle, and the depth of resection will depend on the thickness of the septum; however, it will rarely be $<10 \mathrm{~mm}$.

If the level of obstruction is distant from the aortic valve, precluding transaortic access, apical left ventriculotomy should be performed to provide access to the midventricular septum. ${ }^{8}$ To confirm complete relief of the LVOT obstruction, we used intraoperative echocardiography and routinely measured the simultaneous aortic and LV ventricular pressures by direct needle puncture before and after myectomy. The patients underwent the surgical ablative procedure using a transaortic approach $(n=45)$, transventricular myectomy $(n=4)$, or combined transaortic and transapical $\operatorname{approach}(\mathrm{n}=3)$. In addition to surgery to relieve the obstruction caused by HCM, 19 concomitant procedures were performed in 16 patients (Table 2).

\section{Follow-up and Analysis}

Statistical analyses were performed using Statistical Analysis Systems software, version 9.1 (SAS Institute, Cary, NC). Descriptive statistics for categorical variables are reported as frequencies and percentages and continuous variables as the mean \pm standard deviation. The KaplanMeier method was used to estimate late survival. Observed late survival was compared using a log-rank test with the expected survival of an ageand gender-matched Minnesota population. In the analysis of functional status, we used the most current follow-up information.

\section{RESULTS}

The mean patient age at repeat myectomy was $38.1 \pm$ 18.9 years, and 18 patients were men $(35 \%)$. All patients had cardiac limitations at reoperation, with symptoms of left heart failure, dyspnea, and fatigability, despite medical treatment with 1 or 2 negative inotropic agents (Table 1). In addition, 11 patients $(22 \%)$ had angina pectoris, and 7 $(14 \%)$ had syncope. Formal exercise tests were recorded for 19 patients, whose functional aerobic capacity was $59 \% \pm 24 \%$ of predicted. Among all the patients, the symptom-free interval after the previous myectomy was $22 \pm 42$ months, and repeat myectomy was performed at a mean of $43 \pm 51$ months after the previous procedure (Table 2).

At reoperation, 5 patients had permanent transvenous pacemakers in place because of complete atrioventricular 


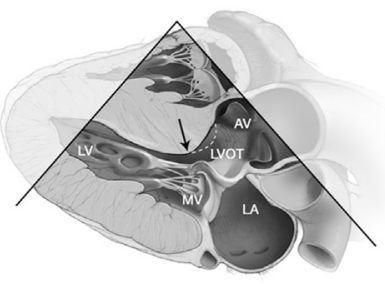

A

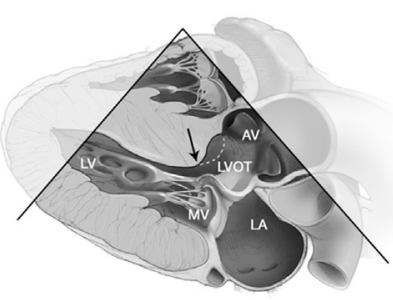

B

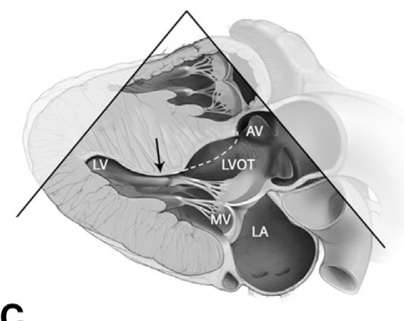

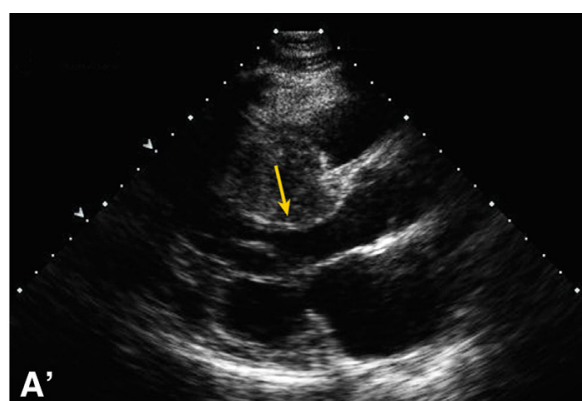
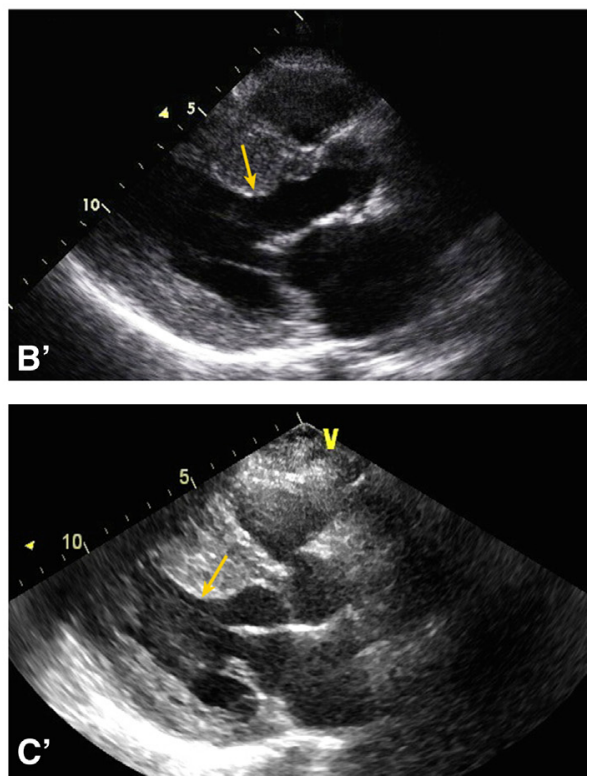

FIGURE 1. Three types of recurrence after septal myectomy for hypertrophic obstructive cardiomyopathy with their respective parasternal long-axis echocardiographic views: A, Inadequate length and depth of excision, (B) inadequate length of excision, and (C) midventricular obstruction at the level of the papillary muscles.

block related to the previous operation. Furthermore, 9 patients had previous implantable cardioverter defibrillator implants, 5 as primary prevention and 4 as secondary prevention, after resuscitation from sudden cardiac death. Dual chamber pacemaker implantations aimed at reducing the LVOT gradients ${ }^{9}$ had been performed at different times before redo myectomy in 9 additional patients.

Before reoperation, 4 subjects were in atrial fibrillation, and 51 were in sinus rhythm or paced as described in the previous paragraphs. Among the patients without pacemakers, the electrocardiograms before repeat myectomy demonstrated normal conduction in 5 patients, left anterior fascicular block in 2 patients, and a left bundle branch block pattern in 44 patients.

The mean peak-to-peak LVOT gradients measured intraoperatively before repeat myectomy were $54 \pm 30 \mathrm{~mm} \mathrm{Hg}$ at rest and $85 \pm 41 \mathrm{~mm} \mathrm{Hg}$ after provocation. After redo myectomy, the maximum (provoked) mean peak-to-peak systolic gradient had decreased to $13 \pm 12 \mathrm{~mm} \mathrm{Hg}$. After redo myectomy, 5 patients required implantable cardioverter defibrillator implantation before hospital dismissal: 2 patients had developed new complete heart block and 2 patients with previous normal intraventricular conduction and 1 with left anterior fascicular block conduction had developed new left bundle branch block.

After surgery, symptom improvement was common. Preoperatively, $96 \%$ of the patients were in New York Heart Association class III or IV, and, postoperatively, 93.8\% were in class I or II $(P<.001$; Figure 2$)$.

\section{Surgical Findings and Causes of Recurrent Obstruction}

The pathologic anatomic findings causing obstruction before reoperation were identified as an inadequate length of excision in 31 patients $(59 \%)$, a combination of an inadequate length and inadequate depth of the previous myectomy in $13(25 \%)$, a combination of an inadequate length and midventricular obstruction in $2(4 \%)$, and isolated midventricular obstruction in 6 patients $(12 \%)$. One patient had 
TABLE 1. Clinical and echocardiographic data from 51 patients undergoing repeat myectomy for obstructive hypertrophic cardiomyopathy

\begin{tabular}{|c|c|}
\hline Variable & Value \\
\hline \multicolumn{2}{|l|}{ Clinical data } \\
\hline Age (y) & $38.1 \pm 18.9$ \\
\hline Male gender & $18(35)$ \\
\hline $\operatorname{BSA}\left(\mathrm{m}^{2}\right)$ & $1.8 \pm 0.4$ \\
\hline Hypertension & $5(10)$ \\
\hline Chronic atrial fibrillation & $4(8)$ \\
\hline History of stroke & $4(8)$ \\
\hline NYHA III-IV & $49(96)$ \\
\hline Previous percutaneous alcohol septal ablation & $3(6)$ \\
\hline Preoperative ICD & $9(18)$ \\
\hline Preoperative pacemaker & $9(18)$ \\
\hline Patient history of sudden death & $4(8)$ \\
\hline Family history of sudden death & $7(14)$ \\
\hline $\begin{array}{l}\text { Preoperative } \beta \text {-blocker or calcium channel blockers } \\
\text { or both }\end{array}$ & $51(100)$ \\
\hline Preoperative diuretics & $17(33)$ \\
\hline \multicolumn{2}{|l|}{ Complications from previous myectomy } \\
\hline Iatrogenic VSD & $4(8)$ \\
\hline Complete AV block & $5(10)$ \\
\hline Aortic valve injury & $6(12)$ \\
\hline \multicolumn{2}{|l|}{ Procedures combined with previous myectomy } \\
\hline Aortic valve replacement & $2(4)$ \\
\hline CABG & $3(6)$ \\
\hline Iatrogenic VSD repair & $3(7)$ \\
\hline Mitral valve repair & $6(12)$ \\
\hline \multicolumn{2}{|l|}{ Measurements } \\
\hline LVOT gradient at rest $(\mathrm{mm} \mathrm{Hg})$ & $54 \pm 30$ \\
\hline Provoked LVOT gradient $(\mathrm{mm} \mathrm{Hg})$ & $85 \pm 41$ \\
\hline $\operatorname{LVEF}(\%)$ & $71.2 \pm 7.8$ \\
\hline Basal septal thickness (mm) & $20.5 \pm 7$ \\
\hline Posterior wall (mm) & $13.3 \pm 3.8$ \\
\hline LVEDD (mm) & $43 \pm 6$ \\
\hline $\operatorname{LVESD}(\mathrm{mm})$ & $24 \pm 5$ \\
\hline LA volume index $\left(\mathrm{mL} / \mathrm{m}^{2}\right)$ & $47 \pm 16$ \\
\hline LV mass index $\left(\mathrm{g} / \mathrm{m}^{2}\right)$ & $171 \pm 74$ \\
\hline Severity of diastolic dysfunction (grade $0-4$ ) & $2.4 \pm 0.9$ \\
\hline $\begin{array}{l}\text { Right VSP }(\mathrm{mm} \mathrm{Hg}) / \text { systemic systolic pressure } \\
\quad(\mathrm{mm} \mathrm{Hg})\end{array}$ & $35.4 \pm 7.8$ \\
\hline $\begin{array}{l}\text { Preoperative exercise test ( } \% \text { functional aerobic } \\
\text { capacity predicted per age)* }\end{array}$ & $60 \pm 24$ \\
\hline Preoperative SAM & $46(88)$ \\
\hline Mitral regurgitation (moderate or greater) & $37(73)$ \\
\hline
\end{tabular}

Data presented as $\mathrm{n}(\%)$ or mean \pm standard deviation. BSA, Body surface area; NYHA, New York Heart Association; ICD, implantable cardioverter defibrillator; $V S D$, ventricular septal defect; $A V$, atrioventricular; $C A B G$, coronary artery bypass grafting; $L V O T$, left ventricular outflow tract; $L V E F$, left ventricular ejection fraction; $L V E D D$, left ventricular end-diastolic diameter; $L V E S D$, left ventricular end-systolic diameter; $L A$, left atrial; VSP, ventricular systolic pressure; $S A M$, systolic anterior motion of mitral valve; $L V$, left ventricular. *Data available for 19 patients.

abnormal papillary muscles combined with midventricular obstruction. Of the 11 pediatric patients (aged $<18$ years) in the present series, recurrence of obstruction had resulted from an insufficient length of septectomy in 9 patients and midventricular obstruction in 2 .
TABLE 2. Intraoperative and postoperative data $(n=51$ patients $)$

\begin{tabular}{lc}
\multicolumn{1}{c}{ Variable } & Value \\
\hline Intraoperative data following repeat myectomy & \\
Extracorporeal circulation time (min) & $63 \pm 37$ \\
Aortic occlusion time (min) & $45 \pm 27$ \\
Amount of septal tissue removed (g) & $5.4 \pm 4.1$ \\
SAM (mild or greater) & 0 \\
Mitral valve regurgitation greater than mild & 0 \\
Residual transventricular gradient (mm Hg) & $13 \pm 12$ \\
Concomitant procedures & $1(2)$ \\
Aortic valve repair & $1(2)$ \\
CABG & $1(2)$ \\
ASD closure & $2(4)$ \\
Tricuspid valve repair & $2(4)$ \\
Tumor removal & $4(8)$ \\
Aortic valve replacement & $4(8)$ \\
Mitral valve repair & $4(8)$ \\
VSD repair & \\
Related surgical complications & \\
Aortic valve injury & \\
New complete atrioventricular block & \\
New iatrogenic VSD & $2(4)$ \\
Intubation $>$ or hospital data & h \\
Median ICU stay (d) & \\
Median hospital stay (d) & \\
\hline Data presented as n (\%) or mean \pm standard deviation. $S A M$, Systolic anterior motion \\
mitral valve; $C A B G$, coronary artery bypass grafting; $A S D$, atrial \\
septal defect;
\end{tabular}

\section{Mitral Regurgitation and SAM}

Preoperatively, mitral regurgitation was common; however, the severity varied in relation to the SAM and dynamic outflow obstruction. If the mitral valve was structurally normal, mitral regurgitation improved or disappeared after myectomy without additional direct procedures on the valve itself. In 4 patients with intrinsic abnormalities of the mitral leaflets, direct valve repair was necessary at myectomy. ${ }^{10}$ No patients required mitral valve replacement.

\section{Early and Late Survival}

No in-hospital mortality occurred; however, 1 patient died after hospital dismissal within 30 days after surgery. The postmortem examination revealed pulmonary embolism. Three late mortalities occurred. One patient with severe pulmonary hypertension died 13 years after surgery of unclear reasons. Another patient died of cancer 11 years after surgery, and 1 patient died of unknown causes 10 years after repeat myectomy. The Kaplan-Meier 10-year survival rate was $98 \%$ and at 15 years was $82 \%$. Survival after repeat myectomy was similar to that of an age- and gender-matched Minnesota population $(P=.46$; Figure 3$)$.

Special attention was given to patients who had had an initial improvement in symptoms and had undergone their first operation at our institution. Among these patients, the 


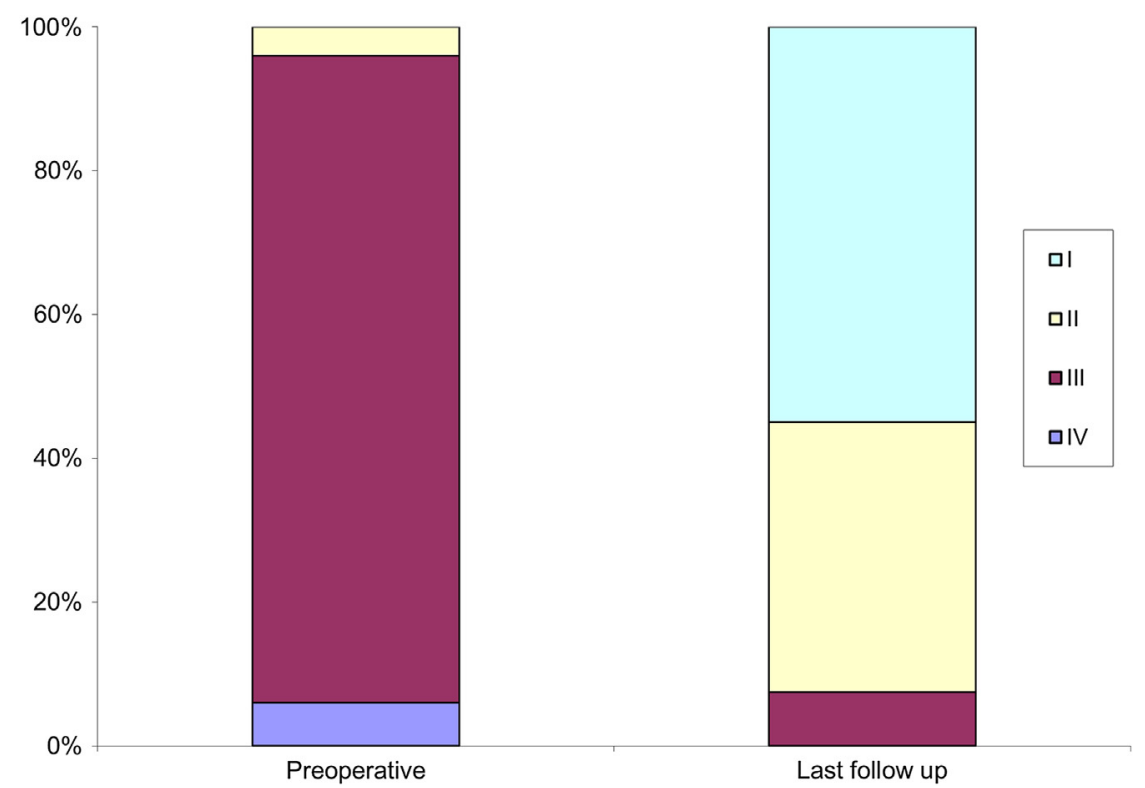

FIGURE 2. Change in New York Heart Association functional class after repeat myectomy. Most patients experienced symptom improvement and were in class I or II $(93.8 \%)$ at the last follow-up visit.

postmyectomy intraoperative LVOT gradients at the initial operation had averaged $9.2 \pm 8.2 \mathrm{~mm} \mathrm{Hg}$, and the symptoms had recurred at an average of $38 \pm 24$ months after

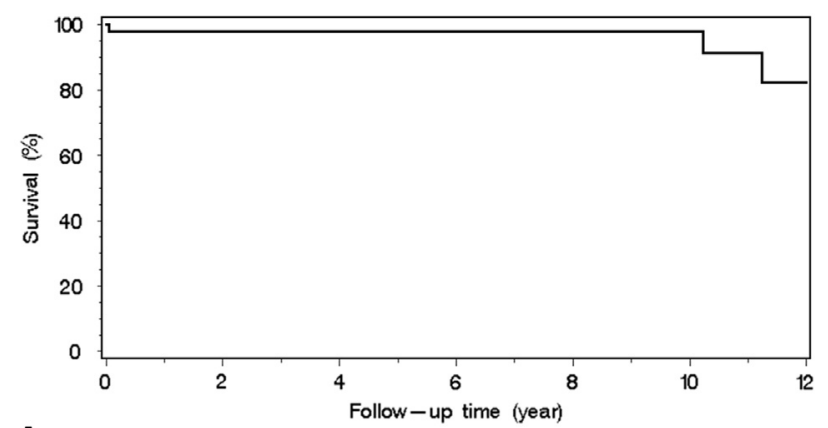

the initial septal myectomy. Detailed comparisons of the intraoperative echocardiograms from the first procedure and those performed just before redo myectomy showed no evidence of regrowth of the subaortic septum. In 2 pediatric patients, the recurrence could be attributed to septal muscle growth at the midventricular level; however, interpretation of the changes was difficult because of somatic growth.

\section{DISCUSSION}

Recurrent symptoms after myectomy for obstructive HCM can be caused by a variety of problems, including LV diastolic dysfunction, valvular abnormalities, development of coronary artery disease, medication-related symptoms, arrhythmias, persistence of pulmonary arterial hypertension, and dynamic or fixed LV obstruction. Little is known about the actual incidence of recurrent obstruction after septal myectomy. However, our subgroup of patients with symptoms and recurrent obstruction severe enough to require reoperation accounted for $1 \%$ of all HCM surgical practice.

Recognition and management of residual or recurrent LVOT obstruction has varied considerably, depending on the quality of clinical assessment and expertise available for this relatively small group of patients. Previously, we reported the outcomes of surgery in 13 patients who had undergone repeat myectomy at our clinic from 1975 to 2003. In that report, the primary cause of LVOT obstruction was identified as limited resection. The results of the present study have provided more detailed information on the morphologic aspects of incomplete septal myectomy in a larger cohort of patients with extended follow-up. 
Assessment of the preoperative echocardiograms and surgical findings revealed that the primary reason for incomplete myectomy was not continuing the septal excision far enough toward the apex during the first operation, and this was identified in $59 \%$ of patients. An additional $25 \%$ of patients had had both inadequate length and depth of the septal excision. Recurrent symptoms due to midventricular obstruction were less common $(12 \%)$.

Several technical factors can limit exposure of the subaortic area and excision of the septal muscle. Visualization of the subaortic septum will often be more difficult in obese patients with thick chest walls and in patients with a greater anteroposterior diameter of the thorax. Also, exposure can be poor because of the small ascending aorta diameter and small aortic valve annulus size. Also important is the level of obstruction and its distance from the aortotomy. Despite these difficulties, in almost all patients, the site of subaortic obstruction can be identified by the presence of the endocardial scar and the area of apposition with the anterior mitral valve leaflet during systolic anterior motion of the structure. It is important that the septal excision be continued distally toward the apex and past the visible endocardial scar.

Understanding the anatomic basis for recurrent LVOT obstruction is important to avoid the complications of myectomy. For example, widening the proximal area of the septal excision in a clockwise direction will increase the risk of injury to the atrioventricular conduction pathway and the development of complete heart block. Also, deepening the region of previous myectomy, because of the mistaken assumption that this is the site of obstruction, will invite the development of an iatrogenic ventricular septal defect.

As a general rule, whenever SAM is present, we have first approached LVOT obstruction through an aortotomy and the aortic valve. However, when midventricular obstruction is present without SAM, we have favored exposure of the midseptum through an apical ventriculotomy. In the present study, 7 patients $(14 \%)$ underwent the transventricular approach for septal myectomy to completely relieve the obstruction. It is likely that some of these patients would have been better served by this approach at their initial operation. Just as is found with subaortic obstruction, an endocardial scar will be present to guide septal the excision in patients with midventricular obstruction. The scar has been caused by contact of the papillary muscles with the septum. Midventricular obstruction can be readily exposed through an apical ventriculotomy, and the procedure is safe, with minimal complications related to incision of the ventricle. $^{11}$

The evolution of gradients deserves special comment. A review of the intraoperative courses of the first myectomy in those patients from our institution (the patients with initial improvement) revealed that the intraoperative LVOT gradients were minimal (mean, $9.2 \pm 8.2 \mathrm{~mm} \mathrm{Hg}$ ). This group had experienced symptom recurrence at $38 \pm 24$ months after the procedure, and a comparison of the septal morphology by echocardiography demonstrated that although the gradients were acceptably low after the initial myectomy, the patients either had some degree of septal bulging that persisted or midventricular obstruction that was not appreciated initially. No evidence from these patients, for whom a direct comparison of the echocardiograms was possible, showed that regrowth of the septal muscle was responsible for the obstruction. As previously described, the pediatric population is at increased risk of recurrent symptoms and the need for reoperation owing to the limited transaortic access that leads to incomplete resections. ${ }^{12}$ It is unclear why these patients had low gradients after the initial myectomy, and it is possible that these had been minimized by anesthetic effects ${ }^{6}$ and/or that the gradients developed later with global LV remodeling. ${ }^{13}$ The interval of reappearance of symptoms could have been influenced by effect of recovery from the heart surgery itself, individual expectations, and physician judgment. It is important, therefore, to measure the intraoperative gradients accurately and compare these with the intraoperative Doppler echocardiographic findings. Provocative maneuvers should be performed (eg, induction of premature ventricular contractions or administration of isoproterenol) to confirm the absence of an inducible gradient. If additional resection is necessary, we will remove more muscle from the distal septum, rather than thinning further the initial myectomy site.

This patient population is complex; nevertheless, the operative mortality for repeat myectomy was very low. Patient survival and symptomatic improvement were similar to those of the larger group of patients undergoing primary myectomy. Indeed, the survival of these patients paralleled that of a gender- and age-matched population. These results emphasize the importance of identifying residual obstruction in patients with persistent symptoms after septal myectomy. These findings also highlight the importance of complete intraoperative assessment of septal myectomy at the initial operation.

\section{CONCLUSIONS}

Reoperation for recurrent obstruction in patients with obstructive HCM is uncommon and but most often required because of an incomplete initial myectomy. The most frequent finding was failure to continue the septal excision far enough toward the apex of the heart. Midventricular obstruction can also lead to recurrent symptoms.

The authors would like to acknowledge Zhuo Li for statistical analysis, Judy Lenoch for data retrieval, Michael King for creation of surgical illustrations, and Mark Zang for echocardiographic imaging support. 


\section{References}

1. Maron MS, Olivotto I, Zenovich AG, Link MS, Pandian NG, Kuvin JT, et al. Hypertrophic cardiomyopathy is predominantly a disease of left ventricular outflow tract obstruction. Circulation. 2006;114:2232-9.

2. Minakata K, Dearani JA, Nishimura RA, Maron BJ, Danielson GK. Extended septal myectomy for hypertrophic obstructive cardiomyopathy with anomalous mitral papillary muscles or chordae. J Thorac Cardiovasc Surg. 2004;127:481-9.

3. Gersh BJ, Maron BJ, Bonow RO, Dearani JA, Fifer MA, Link MS, et al. 2011 ACCF/AHA guideline for the diagnosis and treatment of hypertrophic cardiomyopathy: a report of the American College of Cardiology Foundation/American Heart Association Task Force on Practice Guidelines. J Thorac Cardiovasc Surg. 2011;142:e153-203.

4. Ommen SR, Maron BJ, Olivotto I, Maron MS, Cecchi F, Betocchi S, et al. Longterm effects of surgical septal myectomy on survival in patients with obstructive hypertrophic cardiomyopathy. J Am Coll Cardiol. 2005;46:470-6.

5. Minakata K, Dearani JA, Schaff HV, O'Leary PW, Ommen SR, Danielson GK. Mechanisms for recurrent left ventricular outflow tract obstruction after septal myectomy for obstructive hypertrophic cardiomyopathy. Ann Thorac Surg. 2005;80:851-6

6. Ashikhmina EA, Schaff HV, Ommen SR, Dearani JA, Nishimura RA, Abel MS. Intraoperative direct measurement of left ventricular outflow tract gradients to guide surgical myectomy for hypertrophic cardiomyopathy. J Thorac Cardiovasc Surg. 2011;142:53-9.

7. Schaff HV, Said SM. Transaortic extended septal myectomy for hypertrophic cardiomyopathy. Oper Techn Thorac Cardiovasc Surg. 2012;17:238-50.

8. Said SM, Schaff HV, Abel MD, Dearani JA. Transapical approach for apical myectomy and relief of midventricular obstruction in hypertrophic cardiomyopathy. J Card Surg. 2012;27:443-8.

9. Erwin JP III, Nishimura RA, Lloyd MA, Tajik AJ. Dual chamber pacing for patients with hypertrophic obstructive cardiomyopathy: a clinical perspective in 2000. Mayo Clin Proc. 2000;75:173-80.

10. Wan CK, Dearani JA, Sundt TM III, Ommen SR, Schaff HV. What is the best surgical treatment for obstructive hypertrophic cardiomyopathy and degenerative mitral regurgitation? Ann Thorac Surg. 2009;88:727-31; discussion 731-2.

11. Kunkala MR, Schaff HV, Nishimura RA, Abel MD, Sorajji P, Dearani JA, et al. Transapical approach to myectomy for midventricular obstruction in hypertrophic cardiomyopathy. Ann Thorac Surg. 2013;96:564-70.

12. Minakata K, Dearani JA, O’Leary PW, Danielson GK. Septal myectomy for obstructive hypertrophic cardiomyopathy in pediatric patients: early and late results. Ann Thorac Surg. 2005;80:1424-9; discussion 1429-30.

13. Deb SJ, Schaff HV, Dearani JA, Nishimura RA, Ommen SR. Septal myectomy results in regression of left ventricular hypertrophy in patients with hypertrophic obstructive cardiomyopathy. Ann Thorac Surg. 2004;78:2118-22.

\section{Discussion}

Dr Nicholas G. Smedira (Cleveland, Ohio). Dr Quintana, excellent presentation. I would like the guests to know that Dr Quintana is a Fellow at the Mayo Clinic from Barcelona.

I would like to congratulate you on a great presentation, it was a well-done report, and I congratulate the surgeons from Mayo Clinic, who have performed $>2000$ myectomies with a $<1 \%$ recurrence rate. This shows that in expert hands this operation is very safe and reliable.

I have 2 questions that are mainly technical. You talk about the length; you mentioned the depth of the resection specimen. The question I am often asked and that I was asked on Saturday, is how do you determine this, how do you determine how far down you go, especially when you have SAM with midventricular obstruction? How do you determine the thickness of the resection specimen? Also, you did not mention in the talk or in the report about the width of your resection. So, could you give us an idea of how you make those determinations both by echocardiography and intraoperatively?

Dr Quintana. Thank you, Dr Smedira, for your comments. I think both questions can be answered through the same concept.
As we said, usually a scar lesion is present and that can guide the resection area. We always study the echocardiogram preoperatively and determine the thickness of the intraventricular septum and that gives us an idea of how much we can resect. Usually it is not less than $1 \mathrm{~cm}$.

Also, we want to make a point here. Usually when a patient has just had an inadequate length of excision at the previous operation, the common mistake has been to perform the myectomy just below the aortic valve, which will lead to ventricular septal defect creation. This emphasizes the need for the myectomy to be continued down below and toward the LV apex.

In terms of the width, we guide the resection by studying the scar tissue and having an idea of where the point of obstruction is.

Dr Smedira. In the small number of patients who have had recurrence of the obstruction, as I understand it, they did not have a provocable gradient in your hands during the first operation.

Dr Quintana. That is true.

Dr Smedira. Also, you measured the septal thickness, and no growth was found. So, it does not regrow, but this suggests, indirectly, that too much septum had been left at the first operation. After seeing that, what would you do differently now to try and avoid that very small number of patients who had had an inadequate resection? Any difference? Are you doing direct pressure measurements, do you think it was missed on the echocardiogram, or did you not take enough muscle?

Dr Quintana. This series of patients had undergone intraoperative direct measurements by needles placed on the ascending aorta and the left ventricle. We are still uncertain why the measurements did not detect these residual gradients after the initial myectomy. There could be several speculations such as that after a pump run and crossclamp time, eventually the myocardium might be stunned, or the needles might have been be in the wrong place But we are unsure about that.

The conclusion we have made from these findings is that we must systematically measure the gradients, that is something we already do, and perhaps pay more attention to any residual significant septal thickness, reviewed on the echocardiogram at surgery.

Dr Daniel H. Drake (Traverse City, Mich). Again, I congratulate you on a spectacular series.

We plan our myectomies using axial echocardiography. We determine the length and depth of the resection from a carefully defined long-axis view, with a goal of leaving a residual septal thickness of approximately $1 \mathrm{~cm}$. In your opinion, is that reasonable?

Dr Quintana. That has been described previously in the series from the Mayo Clinic. At least $1 \mathrm{~cm}$ should be left in the septum to prevent any potential ventricular septal defect creation, even after surgery.

Dr Drake. Thank you.

Dr Gilles D. Dreyfus (Monte Carlo, Monaco). I want to congratulate you on your presentation. I am, however, a bit surprised that you hardly mentioned the mitral valve as a major component of HCM. When you have SAM and a mitral valve that is regurgitant, in the series I have done, with a number that is far less than that at the Mayo Clinic but still a significant number, about 20, 25, we have always treated the mitral valve. SAM is created by a posterior leaflet that is too high and covers the septum and anterior leaflet. Not only that, but once you have trimmed the septum through the aortic valve, if you detach the anterior leaflet of 
the mitral valve, you can resect the septum, because you perfectly align with the septum. Thus, you treat, not only the muscle, but also the mitral valve by extending the anterior leaflet and pushing the coaptation point backward, away from the septum.

So I am a bit surprised, because, really, if I wanted to be a bit provocative, I would say that HCM is nearly a mitral valve disease and hardly a muscle disease, and you are treating this just through the muscle. So would you comment, please, on that. Thank you.

Dr Quintana. Thank you for your comments. I am happy that you brought up this point. This is an important concept, and it is usually mentioned.

We see the issue the other way around. We think that the mitral valve regurgitation is a problem secondary to septal hypertrophy. We have not seen problems with mitral regurgitation due to SAM after resecting the hypertrophic septum that was causing the obstruction. So, usually if myectomy is appropriate, the mitral valve regurgitation will resolve, except if intrinsic mitral valve disease is present, such as degenerative disease or whatever. However, if the mitral valve is structurally normal, nothing needs to be done on the mitral valve, just an appropriate myectomy.

Dr Marc Ruel (Ottawa, Ontario, Canada). One more comment and question about refractory SAM. What has worked well in our hands has been to use an edge-to-edge repair, or an Alfieri stitch, if you will, with excellent results.

Returning to your series, $88 \%$ of patients had SAM. In some cases, the disease was more than just hypertrophy but also included distortion of the left ventricle and the relationship of the mitral valve to the septum. Did you use the Alfieri repair in your series?

Dr Quintana. Thank you very much. None of these patients had undergone an Alfieri procedure. Only 4 patients underwent mitral valve repair for intrinsic mitral valve disease, and that was resection of prolapsing segments and, eventually, a protective annuloplasty.

Dr Leonard N. Girardi (New York, NY). Dr Quintana, I have 1 question. If you consider the 20 patients from Mayo, it was about 3.5 years from the first operation to the second. If you review their initial echocardiograms coming out of the operating room, what sort of LVOT gradients and how much mitral regurgitation did they have coming out of the operating room after their first operation? How much should we tolerate before we reclamp, go back in, and do something else about the mitral valve, as was just mentioned, or should we do some more resection?

Dr Quintana. Thank you for your question. These patients did not have systolic anterior motion detected just after myectomy in the operating room nor a gradient detected by direct needle placement. Thus, we still do not quite understand why we were not able to detect these persistent gradients. We have not seen muscle regrowth, but I think if any significant systolic anterior motion and associated mitral regurgitation is present, anything, probably, more than mild mitral regurgitation in the context of SAM, it should probably be reassessed surgically. 